\title{
Development and Analysis of Pulse Width Modulation Techniques for Induction Motor Control
}

\author{
SUNNY KATYARA*, ASHFAQUE AHMED HASHMANI**, BHAWANI SHANKAR CHOWDHARY**
}

RECEIVED ON 05.09.2018, ACCEPTED ON 19.02.2019

\begin{abstract}
SVPWM (Space Vector Pulse Width Modulation) technique is type of traditional PWM method that efficiently utilizes its de link voltage and generates high voltage pulses with low harmonic content and high modulation index. VSI (Voltage Source Inverter) with SVPWM generates adjustable voltage and frequency signals for VSDs (Variable Speed Drives). This research work presents the simplified SVPWM technique for controlling the speed and torque of induction motor. The performance of developed SVPWM technique is analyzed in terms of its switching losses and harmonic content and compared with SPWM (Sinusoidal Pulse Width Modulation). Mathematical modeling for induction motor control through two-level VSI with SVPWM and SPWM is presented. The voltage and current TDHs (Total Harmonic Distortions) of the drive with SVPWM technique are 73.23 and $63.3 \%$ respectively as compared to 101.99 and $77.89 \%$ with SPWM technique. Similarly, the switching losses with SVPWM technique are $178.79 \mathrm{~mW}$ and that of with SPWM are $269.45 \mathrm{~mW}$. Simulink modeling and laboratory setup are developed to testify the efficacy of SVPWM and SPWM techniques. The modulation factor of SVPWM technique is 0.907 which is higher as compared to SPWM technique with 0.785 modulation factor.
\end{abstract}

Key Words: Space Vector Modulation, Total Harmonic Distortion, Switching Losses, Induction Motor, Voltage Source Inverter, SinnsoidalPulse Width Modulation

\section{INTRODUCTION}

W

ith growing use of VSDs in industrial applications, the VSIs have been given more importance. The main reason of increased popularity of VSI is their ability to transform higher voltages at low harmonics contents. IGBTs (Insulated Gate Bipolar Transistors) have replaced thyristors because of their efficient switching capability and higher power rating. VSIs operate in a controlled mode and convert constant de link voltage into ac voltage of varying amplitude, frequency and phase [1].

VSDs are used to control speed and torque of deployed induction motors in industries. The schematic arrangement for controlling the induction motor through VSD is shown in Fig.1.

Authors E-Mail: Sunny.katyara@iba-suk.edu.pk, ashfaque.hashmani@faculty.muet.edu.pk, bhawani.shanker@faculty.muet.edu.pk

* Department of Electrical Engineering, Sukkur IBA University Pakistan

** Department of Electronic Engineering, Mehran University of Engineering and Technology, Jamshoro

This is an open access article published by Mehran University Research Journal of Engineering and Technology, Jamshoro under the CC by 4.0 International License. 
Since, induction motor is inherently being supplied with constant input voltage and frequency and it generates unvarying torque at constant speed [2]. In order to adjust the torque and speed of induction motor, its input voltage and frequency should be regulated. The ConverterInverter topology is set to produce variable voltage and frequency for VSDs.VSI is invariably being used in VSDs.

The PWM technique is used to harmonize the output of VSI. With PWM technique, the desired output waveform can be obtained by varying its switching time. With three pole-two level inverter, the output voltage is based on condition of dc link voltage at different eight states. The two-level-three pole inverter consisted of six IGBTs as shown in Fig.2.
The PWM techniques for switching the VSI control the magnitude and frequency of its output. The VSI converts constant DC link voltage into variable AC output. The efficiency and harmonics content of VSI principally rely upon the modulation technique used to adjust the parameters of inverter [3]. The SPWM (Sinusoidal PWM) is characterized by constant magnitude with varying duty cycle of each phase. The modulating signal varies the width of these pulses to control the output of VSI and also to diminish harmonics in its output. SPWM is the simplest technique for controlling drives. Triangular carrier wave and sinusoidal modulating wave are used to generate SPWM. The ratio of carrier and modulating signals must be an integer $2 \mathrm{~N}$, that determines the number of voltage pulses per cycle [4]. While SVPWM is an

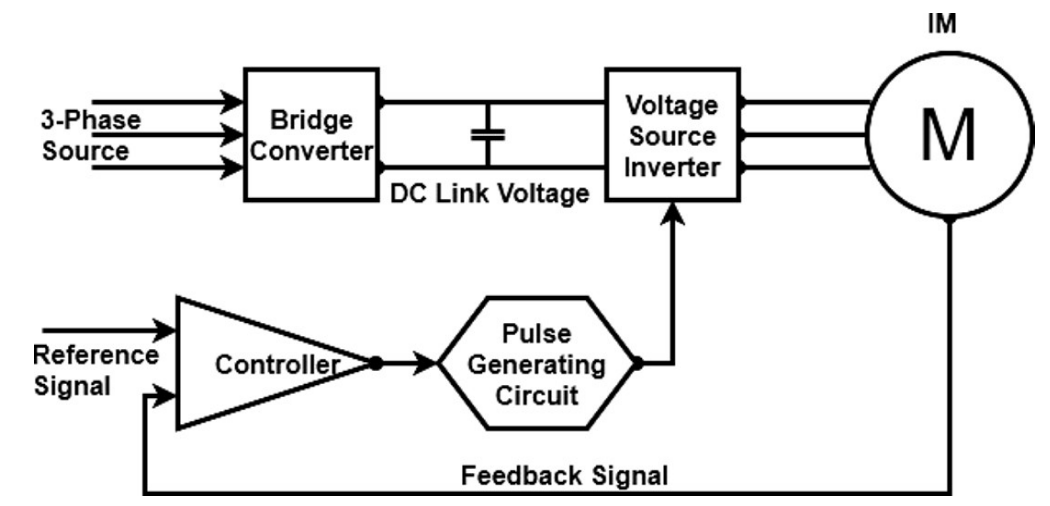

FIG.1. CONTROLLING CIRCUIT OF INDUCTION MACHINE

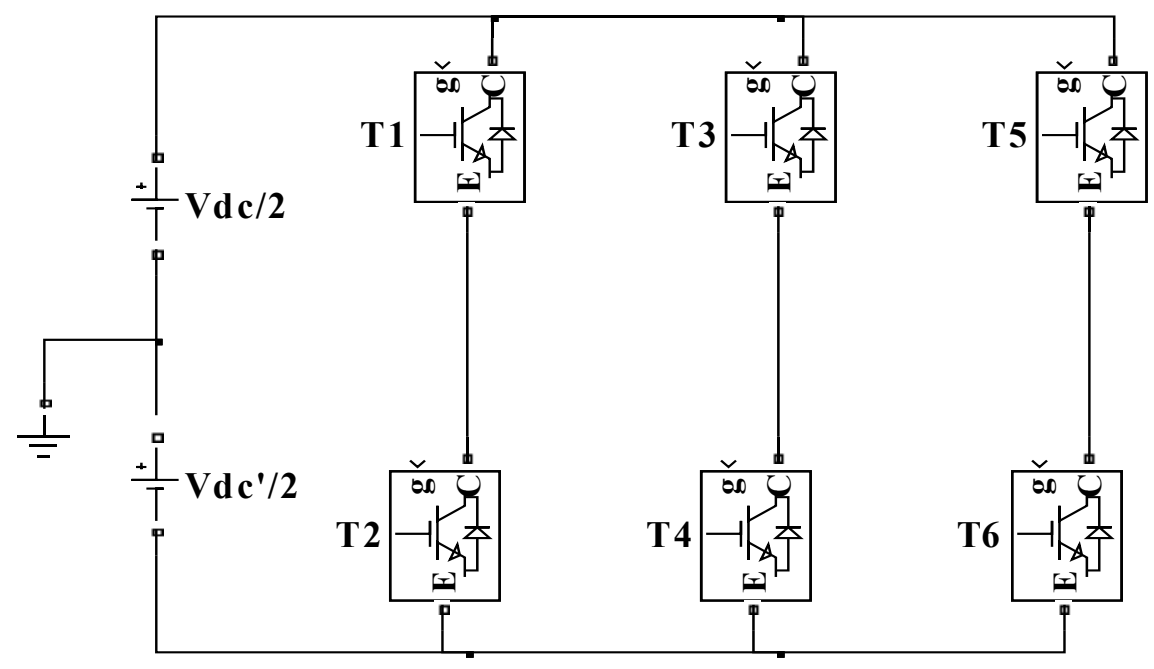

FIG.2. TWO LEVEL-THREE POLE VOLTAGE SOURCE INVERTERCONFIGURATION 
alternative controlling technique with combined effect of three phases, which is called space vector. Space vector rotates with uniform velocity and tip of vector trace the circle with sinusoidal excitation. For two-level inverter, the actives states are framed according to synthesize the output voltage at desired harmonic level. The main advantage of using SVPWM is that it utilizes the dc link potential at maximum extent as compared to SPWM technique [5].

Hyeong et. al [6] presented the modified Space Vector PWM technique for three level VSI using IGBTs. They developed an algorithm for controlling the neutral point dc link voltage and analyzed the results on the basis of switching and execution frequencies. Busquets-Monge et. al.[7] exercised the neutral point potential control of three level voltage source inverter using concept of virtual space vector modulation. The designed technique was feasible with linear as well as non-linear loads at zero current output of inverter. The comparison analysis of PWM technique was made with phase duty ratio approaches at different modulation indices and reference angles. Leedy et. al.[8] determined the power quality of generated SVPWM signal by calculating its Fourier coefficients. Positive and negative factors of SVPWM were used to directly estimate the harmonic content of the pulse without using any rigorous algorithms. With this approximation, the harmonics analysis of not only twolevel converters but higher level converters could be analyzed in a similar way. Lee et. at.[9] discussed the Space Vector PWM for multilevel matrix converters with aim of reducing harmonic content at lower modulation indices. The I3SMC (Indirect Three Level Spare Matrix Converter) was used to synthesize the balanced output voltages with neutral point potential clamping. The basic operating principle of matrix converters was explained with merits and demerits. Yuan et. al.[10] proposed space vector PWM for VSIs using ANN (Artificial Neural Network) trained through Levenberg-Marquarde algorithm. The designed technique was so efficient enough to exclude non-linearity during computations and developed ANN reduced switching timing and power quality of system with least harmonic contents. Nayeemuddin et. al. [11] evaluated the new aspects of space vector PWM method by addressing the issues of acoustic noise and harmonic contents. The proposition for induction motor was visualized with three different aspects i.e. adjustable random delay in PWM, random single zero vector PWM and random double zero vector PWM.

This research work presents the simplified SVPWM technique for controlling the speed and torque of induction motor. The performance of developed SVPWM technique is analyzed in terms of switching losses and THD. A comparative study between SPWM and SVPWM is also being carried out, to figure out the performance of both techniques. A detailed mathematical and Simulink modeling of system for controlling the output of induction motor is developed to validate the efficacy of propositions. Finally, laboratory setup is arranged to verify the constant voltage and frequency (U/F) ratio with PWM control of induction motor drive.

\section{RESEARCH METHODOLOGY}

\subsection{Space Vector Pulse Width Modulation}

SVPWM is the modified switching technique in which three voltage phasors are transformed into two vectors in orthogonal coordinates [12-13]. For two-level inverter all the active voltage states lie along the radii of hexagon as shown in Fig.3. The reference space vector should trace the circular trajectory based on the eight vector states. In the motor drive applications, with variations in the frequency the corresponding changes in the amplitude of reference voltage vector occur. The rotating reference voltage space vector $\mathrm{V}_{\text {ref }}$ is sampled at higher frequency $\mathrm{f}_{\mathrm{s}}[12-13]$. With greater sampling frequency, accurate sine wave can be obtained but it causes higher switching losses too.

Mehran University Research Journal of Engineering \& Technology, Volume 39, No. 1, January, 2020 [p-ISSN: 0254-7821, e-ISSN: 2413-7219] 
The reference vector is obtained by joining the two respective supply voltage vectors to gathers. When the reference vector is located in sector 1 as shown in Fig.4, the switching time is calculated by Equations (1-2) [12-13].

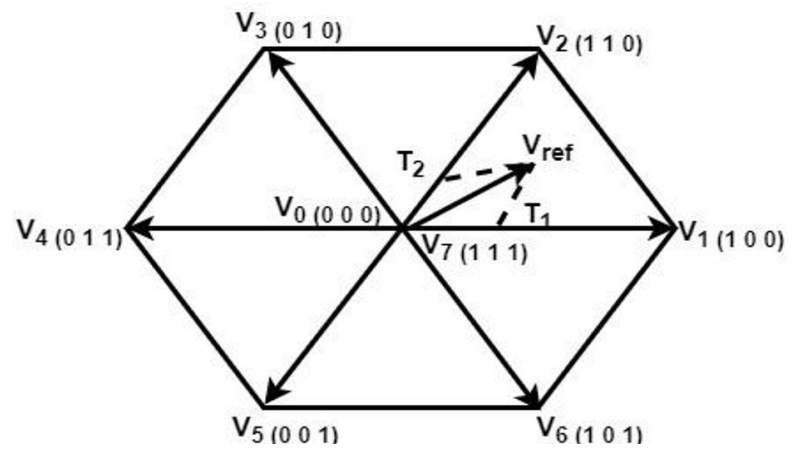

FIG.3. TRAJECTORY OF VOLTAGE SPACE VECTOR

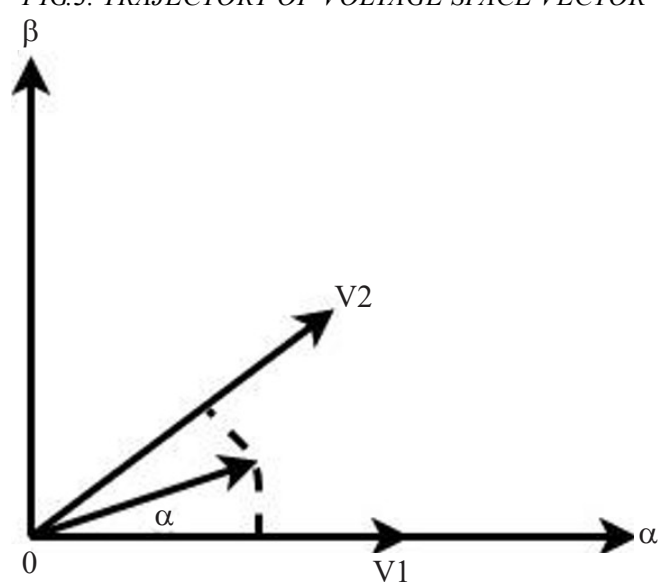

IG.4. SYNTHESIS OF REFERENCE VECTOR IN SECTOR 1 $O N \alpha-\beta$ PLANE
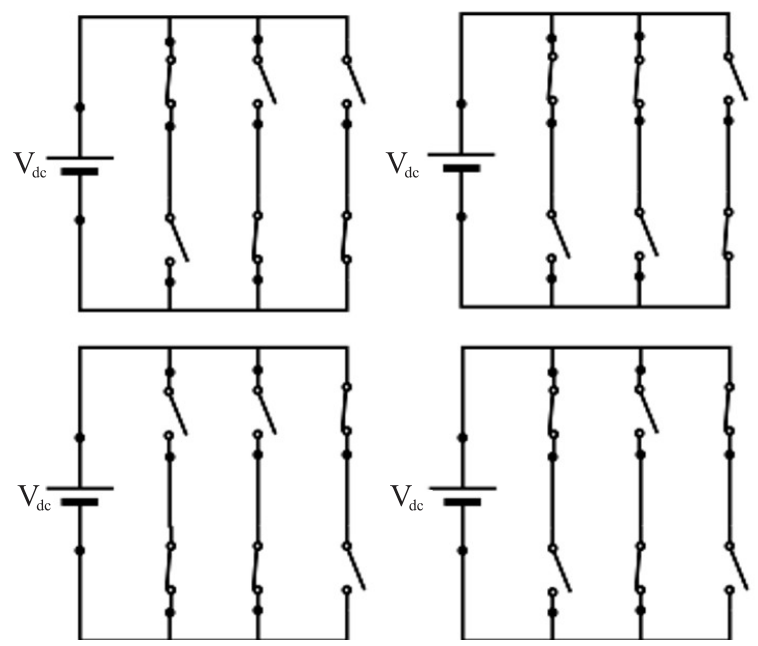

$$
\begin{aligned}
& \int_{0}^{T z} V_{r e f}=\int_{0}^{T 1} V_{1} d t+\int_{T 1}^{T 1+T 2} V_{2} d t+\int_{T 1+T 2}^{T z} V_{0} \\
& T_{Z} V_{r e f}=T_{1} V_{1}+T_{2} V_{2}
\end{aligned}
$$

Where $T_{Z}=1 / f_{z}$ and $f_{z}$ is carrier frequency.

In the way, the switching timings for other remaining five sectors can be calculated by using Equations (1-2) with respective input variables.

Since the VSI is consisted of six IGBT switches arranged in pair of two in three different arms, as shown in Fig.5. The upper switches are designated as T1, T2, and T3 while the bottom switches are T2, T4 and T6, to control the drive. The states of uppers switch determine the output voltage.

$$
\begin{aligned}
& {\left[\begin{array}{l}
V_{\alpha} \\
V_{\beta}
\end{array}\right]=\frac{2}{3}\left[\begin{array}{ccc}
1 & -\frac{1}{2} & \frac{1}{2} \\
0 & \frac{\sqrt{3}}{2} & -\frac{\sqrt{3}}{2}
\end{array}\right]} \\
& \alpha=\tan ^{-1}\left(\frac{V_{\beta}}{V \alpha}\right) \\
& V_{r e f}=\sqrt{\left(V_{\alpha}^{2}+V_{\beta}^{2}\right.}
\end{aligned}
$$
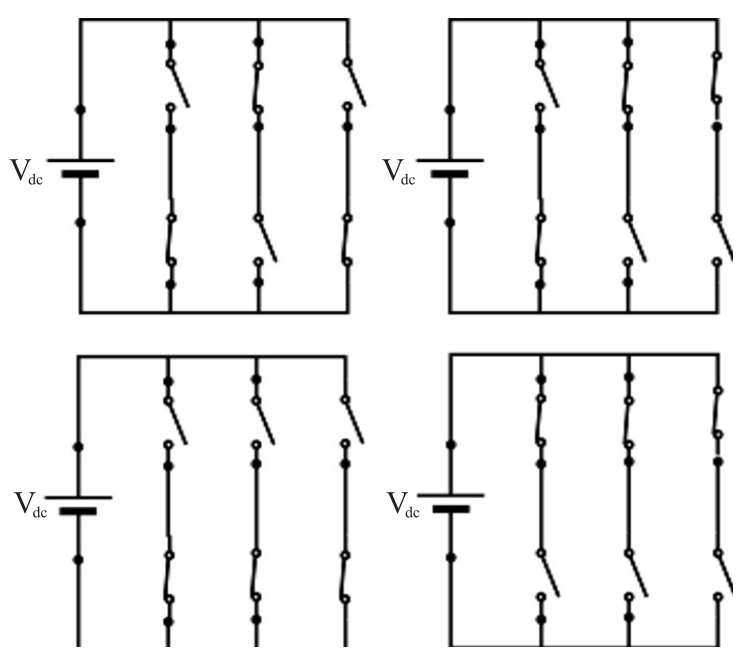

FIG.5. EIGHT STATES OF IGBT SWITCHES FOR SVPWM 
In order to implement SVPWM, the voltages in three phase planes are transformed into two phase $\alpha-\beta$ plane as given by Equation (3) [12-13]. Switching sequence of upper switches T1, T2 and T3 is shown in Fig.6. The reference vector $\left(\mathrm{V}_{\text {ref }}\right)$ starts from zero states (000 or 111) and moves to corresponding active states and in sector 1 , it is (100). The vector V1 and V2 has respective switching timing of $\mathrm{T} 1$ and $\mathrm{T} 2$

\subsection{Sinusoidal Pulse Width Modulation}

SPWM is one the most commonly used PWM techniques. The SPWM is also called carrier-based PWM. It uses reference modulation signal to generate the desired output voltages. It is called SPWM because it uses sinusoidal modulating signal whose maximum value is always less than the maximum value of carrier signal [14]. The principle of SPWM is shown in Fig.7. The sinusoidal modulating signal of $50 \mathrm{~Hz}$, also called reference signal is modulated by high frequency triangular carrier signal. By comparing modulating wave with carrier wave, switching signal is generated. The pulse is generated when magnitude of modulating wave is larger than carrier wave and this switching pulse is then used to activate the switches of VSI.

\subsection{Induction Motor}

Three phase Induction motor drive is widely used in industrial applications for process control. It is consisted of stator and rotor circuits. Per unit quantities are used to describe the mathematical model of induction motor. The equations are written in arbitrary reference frame, moving with angular speed of $n_{k}$. The Equations (4-7) [15] represent the voltages and fluxes of stator and rotor circuits.

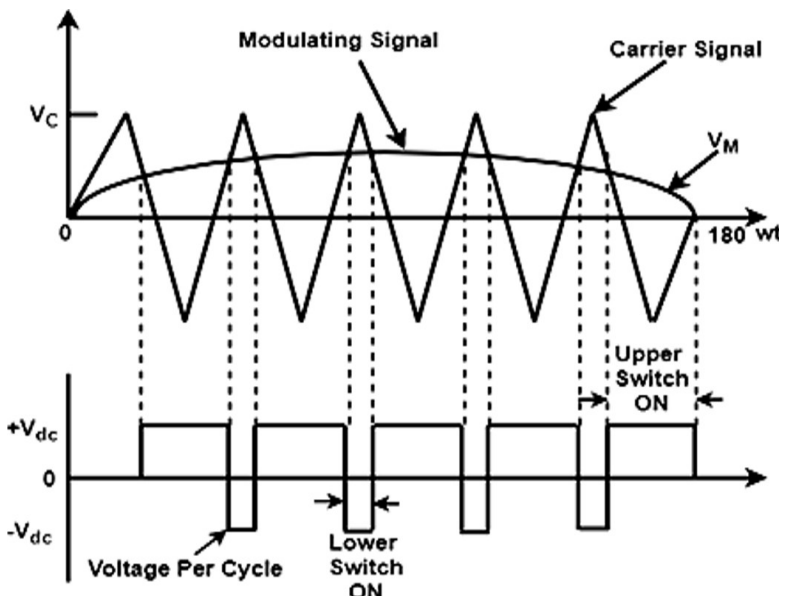

FIG.7. BASIC PRINCIPLE OF SINUSOIDAL PWM

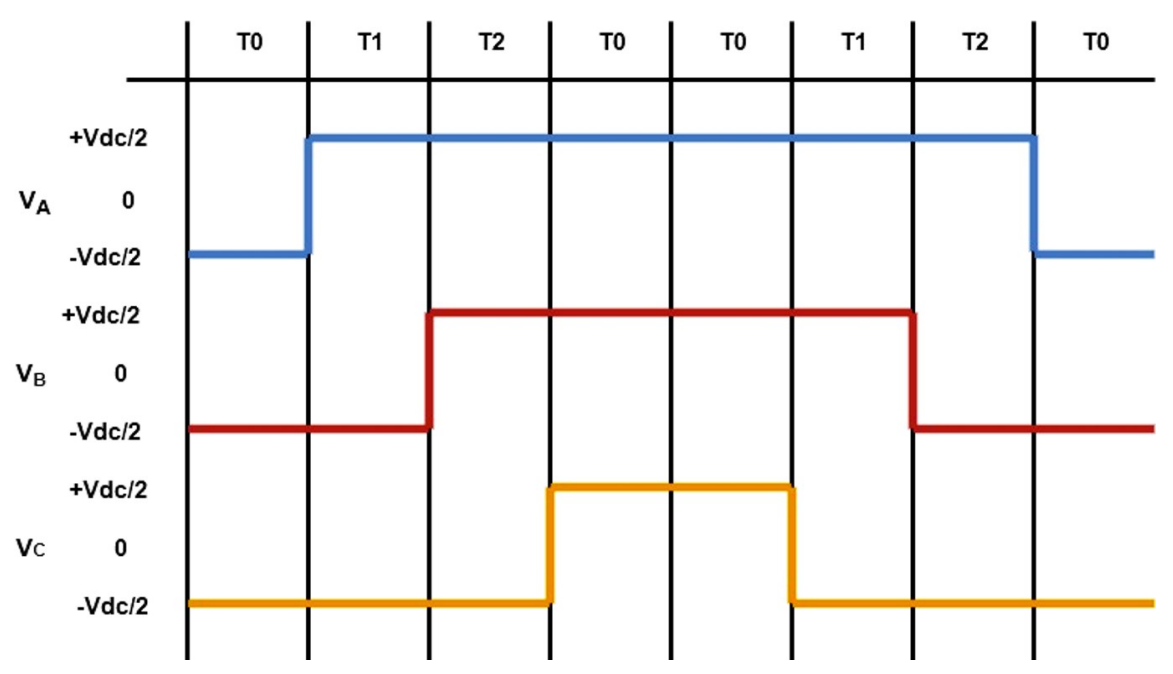

FIG.6. SWITCHING SEQUENCE IN SECTOR-1 
$V_{S}=I_{s} R_{s}+T_{N} \frac{d}{d t} \varphi_{S}+j n_{k} \varphi_{S}$

$0=I_{s} R_{s}+T_{N} \frac{d}{d t} \varphi_{R}+j\left(n_{k}-n_{m}\right) \varphi_{R}$

$\varphi_{S}=I_{S} R_{S}+L_{m} I_{R}$

$\varphi_{R}=L_{R} I_{R}+L_{m} I_{S}$

Equations (8-10)[14] represent shaft angle, equation of motion and electromagnetic torque.

$T_{N} \frac{d \phi_{m}}{d t}=n_{m}$

$\frac{d n_{m}}{d t}=\frac{1}{T_{M}}\left(m_{e}-m_{0}\right)$

$m e=\operatorname{lm}\left(\varphi_{S} I_{S}\right)=\varphi_{s \alpha} I_{s \beta}-\varphi_{s \beta} I_{s \alpha}$

Where $\mathrm{V}_{\mathrm{s}=} \mathrm{V}_{\mathrm{s} \pm}+\mathrm{jV}_{\mathrm{s}^{2}}-$ Vector stator voltage, $\mathrm{I}_{\mathrm{s}=} \mathrm{I}_{\mathrm{s} \pm}+\mathrm{jI}_{\mathrm{s}^{2}}-$ Vector stator current, $I_{s=} I_{r \pm}+j_{r^{2}}-$ Vector rotor current, $q_{s}$ $=\mathrm{q}_{\mathrm{s}^{ \pm}}+\mathrm{jq}_{\mathrm{s}^{2}}-$ Vector stator flux, $\mathrm{q}_{\mathrm{r}=} \mathrm{q}_{\mathrm{r}^{ \pm}}+\mathrm{jq}_{\mathrm{r}^{2}}-$ Vector rotor flux, $\mathrm{L}_{\mathrm{s}}-$ Stator inductance, $\mathrm{R}_{\mathrm{s}}-$ Stator resistance, $\mathrm{L}_{\mathrm{r}}-$ Rotor inductance, $\mathrm{R}_{\mathrm{r}}-$ Rotor resistance, $\mathrm{T}_{\mathrm{M}}-$ Mechanical time constant, $\varnothing_{\mathrm{m}}-$ Shift angle of motor, $n_{m}, m_{e}, m_{o}-$ Angular speed, electromagnetic and load torques, and $\mathrm{T}_{\mathrm{N}}$ - Nomial time constant

\subsection{Total Harmoinc Distortion}

THD is a measuring index which determines how much voltage or current signals are distorted due to the presence of harmonics. Mathematically, it is ratio of RMS value of all harmonics of voltage or current signals to the RMS value of fundamental frequency of voltage or current signals respectively. The mathematical expression for THD calculation is given by Equation (11) [16]. Since, the magnitudes of harmoincs are required for calculating
THD of signal, therefore Fourier technique can be used to estimate the individual values of all harmonics, starting from order 2 upto maximum 40 [16].

$$
\operatorname{THD}_{U} \equiv \sqrt{\sum_{2}^{40}\left(\frac{V_{h}}{V_{1}}\right)^{2}} \times 100
$$

Where: $V_{h}$ is magnitude of harmonics voltage and $V_{l}$ is magnitude of fundamental voltage.

\subsection{Switching Losses}

The performance of inverter mainly depends upon its conduction and switching losses, which collectively are power losses. However, the switching losses depend upon the supply frequency, supply voltage, load current and dynamics of inverter [17]. These losses can be eliminated by using soft switching technique. These losses are high in VSI and can be controlled by varying the duty cycle of switching pulse. The inverters with high power ratings require switching signal of lower frequency, thus the nominal current of inverter increase [17]. With this, although switching losses decrease but the conduction losses are increased correspondingly. The snubber circuit plays vital role in controlling the magnitude of switching losses in the inverter.

Equation (12) [16] is used to estimate the tun-on losses of IGBT based inverter caused by load current.

$$
P_{O N}=0.167 \times F_{\text {out }} \times V_{D C} \times T_{R} \times I_{L P} \times \sum_{m-1}^{\frac{m f}{2}} \sin \left(m \frac{2 \pi}{m f}\right)
$$

Due to discharging of capacitor in snubber circuit of inverter circuit, the value of switching losses is little higher. The turn-off losses of IGBT based inverter is calculated by Equation (13) [16]. 
$P_{\text {OFF }}=\frac{1}{7.4} \times F_{\text {out }} \times T_{F} \times I_{L P} \times \sum_{m=1}^{\frac{m f}{2}}\left[\sin \left(m \frac{2 \pi}{m f}\right)\left(V_{D C}+\sqrt{\frac{L_{S}}{C_{S}} I_{L P}} \times \sin \left(m \frac{2 \pi}{m f}\right)\right)\right]$

Where $\mathrm{F}_{\text {out }}$ - Output voltage frequency, $\mathrm{V}_{\mathrm{DC}}-\mathrm{DC}$ link voltage inverter, $T_{R}-$ Rise time during turning on, $T_{F}-$ Fall time during turning off, $\mathrm{I}_{\mathrm{LP}}-$ Peak load current of $1^{\text {st }}$ harmonics, $\mathrm{m}$ - Switching state in half cycle of output voltage, $\mathrm{L}_{\mathrm{S}}$ and $\mathrm{C}_{\mathrm{S}}-$ Snubber circuit inducatance and capacitance, and $\mathrm{M}_{\mathrm{f}}-$ Operation period

\subsection{Simulink Modeling}

The Simulink models of IM (Induction Motor) controlled through VSI switched by SVPWM and SPWM are shown in Figs. 8-9 respectively. The common parameters of circuit are shown in Table1. The PI speed controller is used to set the reference values both SVPWM and SPWM. The step load torque is applied to IM drive.

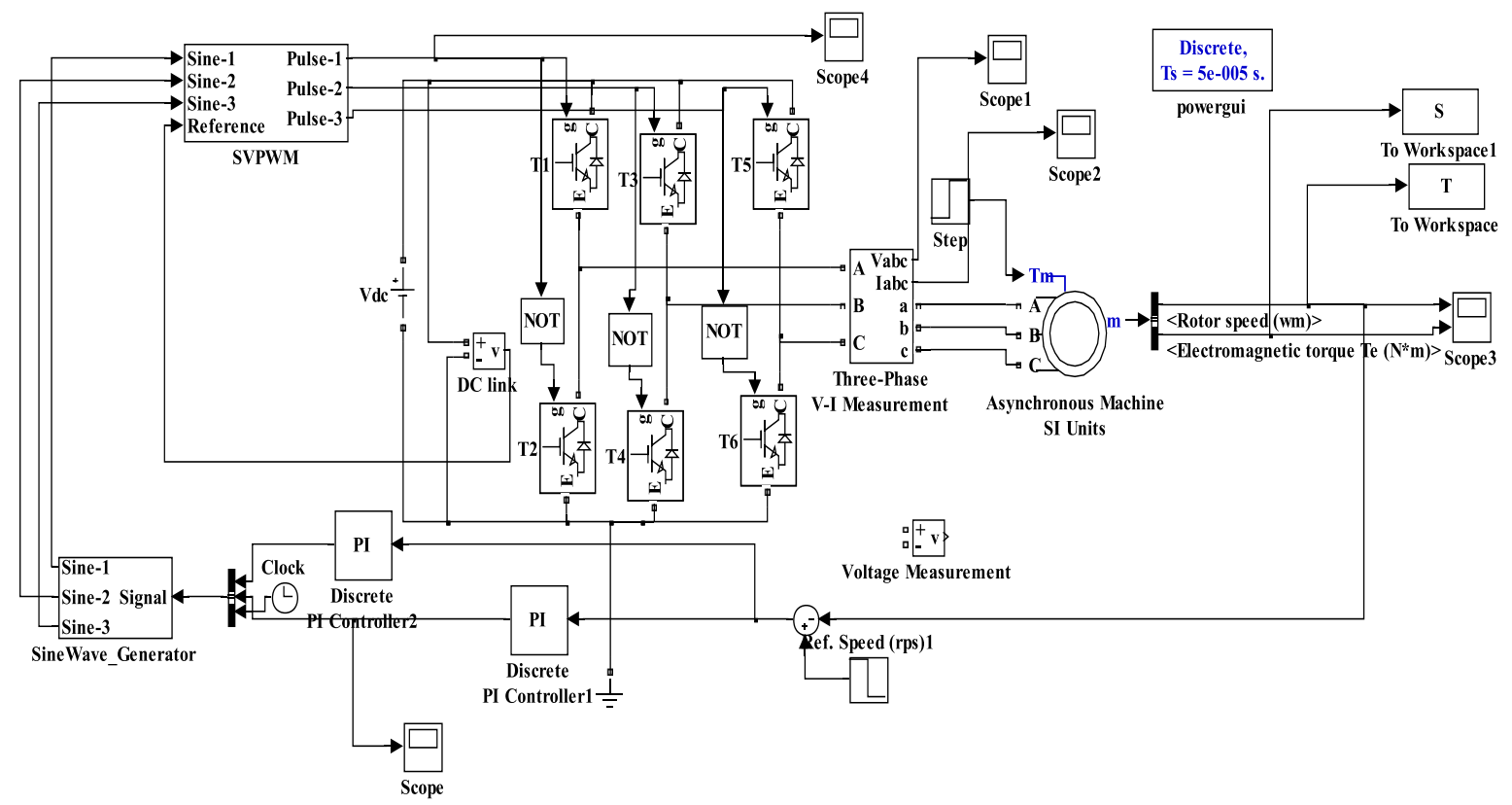

FIG.8. SIMULINK MODEL OF SVPWM CONTROL OF INDUCTION MOTOR

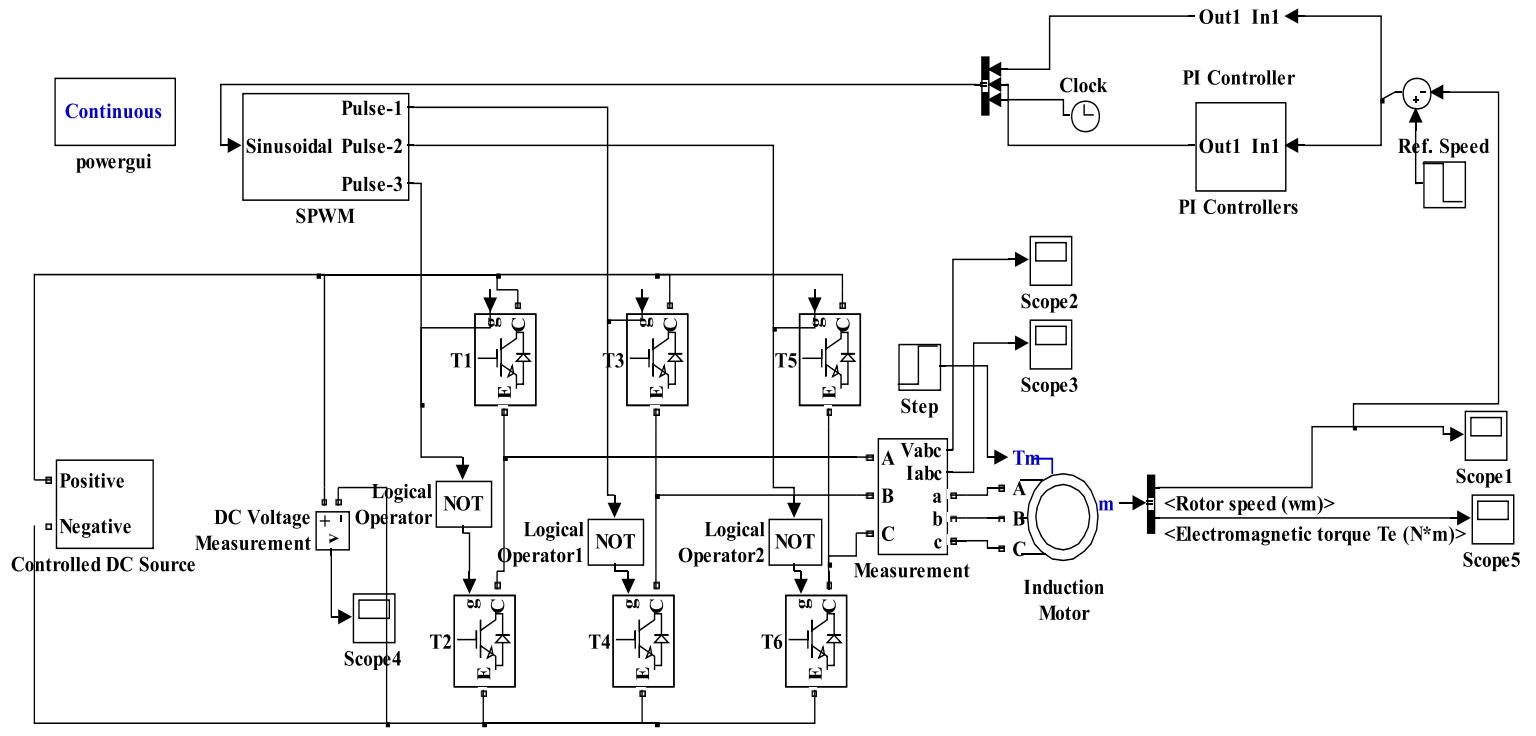

FIG.9. SIMULINK MODEL OF SPWM CONTROL OF INDUCTION MOTOR 


\section{RESULTS AND DISCUSSION}

\subsection{Simulink Results}

The voltage and current inputs to the motor with SVPWM method and its corresponding harmonics analysis are shown in Figs.10-11. Since, pure sinusoidal waveform is not obtained due to varying speed of induction motor which is given feedback through PI-controller. The THDs for inverter output voltage and currents are 73.23 and $63.30 \%$ respectively. The switching signal for IGBT inverter switches is shown in Fig.12. It is being modulated between 0 and 1, at a modulation index of 0.907 . The rotor speed of induction motor is shown in Fig. 13, which gets normalized at $150 \mathrm{rpm}$. The electromagnetic torque of IM drive is shown in Fig. 14 and it reaches to 60 N.m with a step load torque. The trajectory of SVPWM technique is shown in Fig.15. The trend of switching losses in VSI with SVPWM technique is shown in Fig.16. The RMS value of switching losses in case of SVPWM is $178.79 \mathrm{~mW}$.

The FFT analysis of output voltage and current of VSI with SPWM method is shown in Figs. 17-18. Fig.17 shows that voltage THD is $101.99 \%$, which is huge because the reference modulating signal is generated with the help of feedback speed signal. Fig. 18 shows that the current THD is $77.89 \%$. The speed of motor reaches to $150 \mathrm{rpm}$ and normalizes to $20 \mathrm{rpm}$ with SPWM, due to consequent fluctuations, as shown in Fig.19. The torque of motor reaches to 200 N.m, as shown in Fig. 20. The switching signal for VSI with SPWM is shown in Fig.21. The switching loss of inverter with SPWM is shown in Fig.22 and reaches to $269.45 \mathrm{~mW}$.

TABLE 1. SYSTEM PARAMETERS

\begin{tabular}{|c|c|}
\hline Parameter & Value \\
\hline DC Link Voltage (VDC) & $650 \mathrm{~V}$ \\
\hline Output Voltage and Current of VSI & $400 \mathrm{~V}$ and $70 \mathrm{~A}$ \\
\hline Gate Resistance & 6.5 ohms \\
\hline Motor power rating & $3.75 \mathrm{Kw}$ \\
\hline Switching frequency & $1.5 \mathrm{kHZ}$ \\
\hline
\end{tabular}
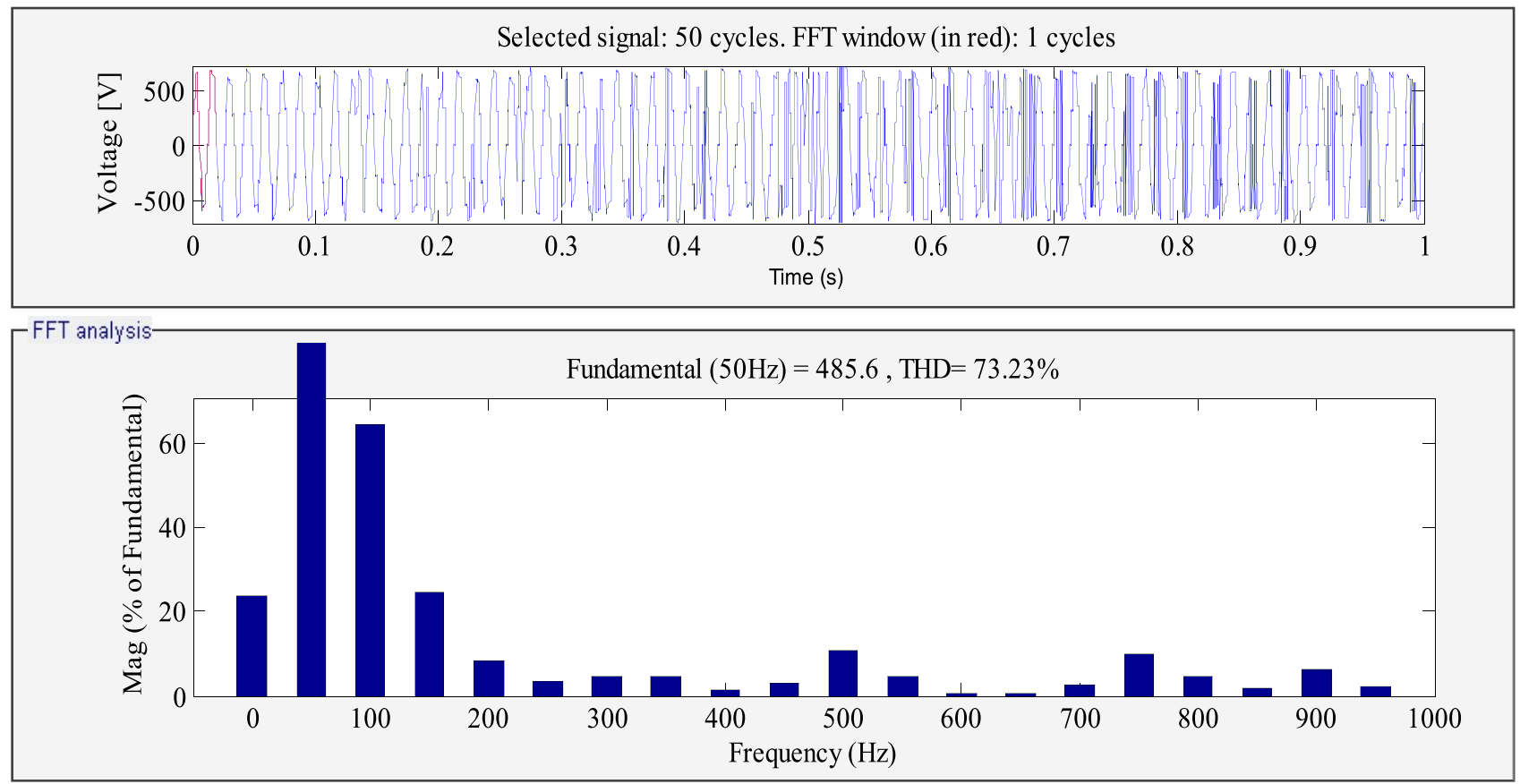

FIG.10. INPUT VOLTAGE TO MOTOR AND ITS HARMONIC ANALYSIS WITH SVPWM 

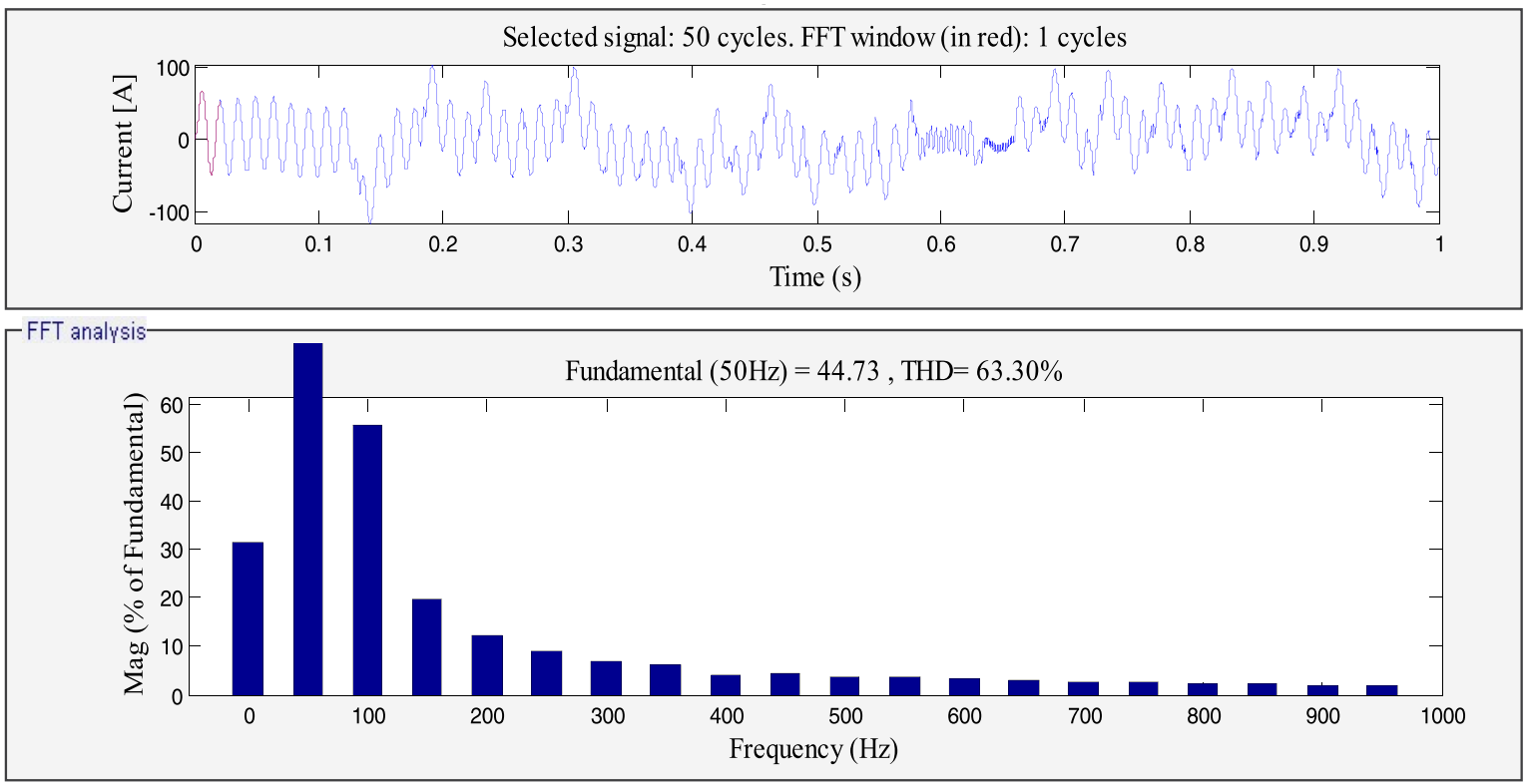

FIG.11. INPUT CURRENT TO MOTOR AND ITS HARMONIC ANALYSIS WITH SVPWM

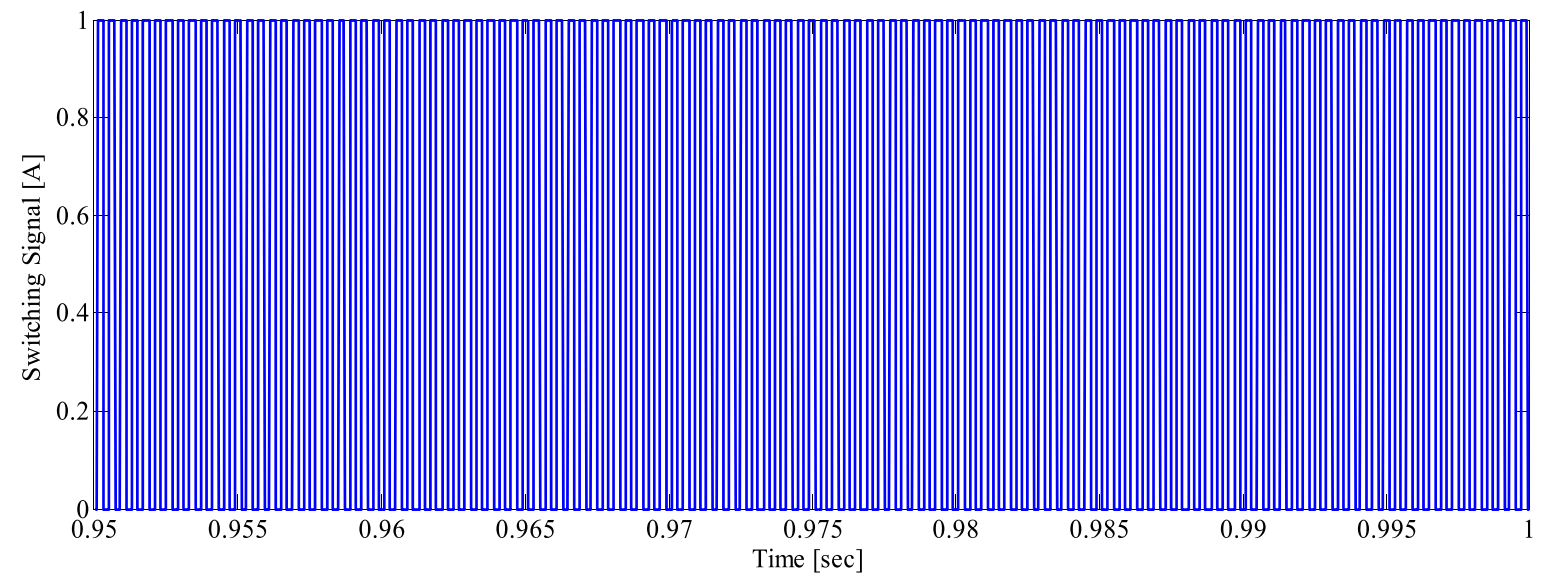

FIG. 12. SVPWM SWITCHING SIGNAL FOR VSI

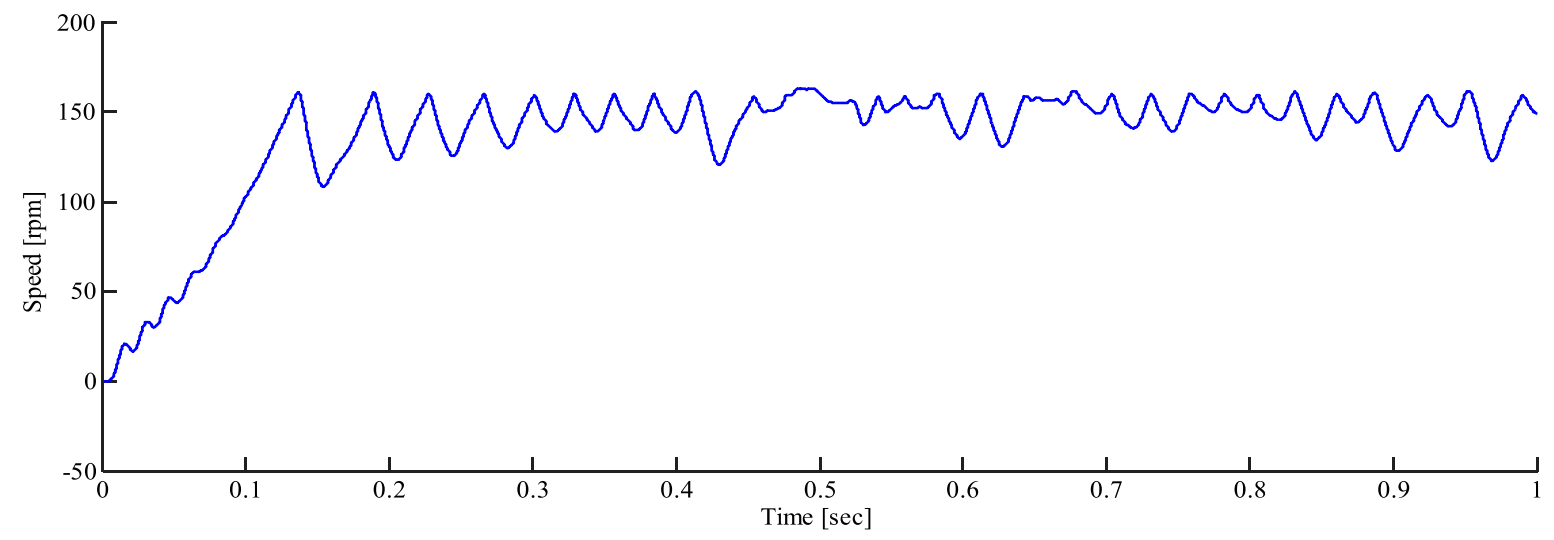

FIG. 13. ROTOR SPEED OF INDUCTION MOTOR DRIVE WITH SVPWM 


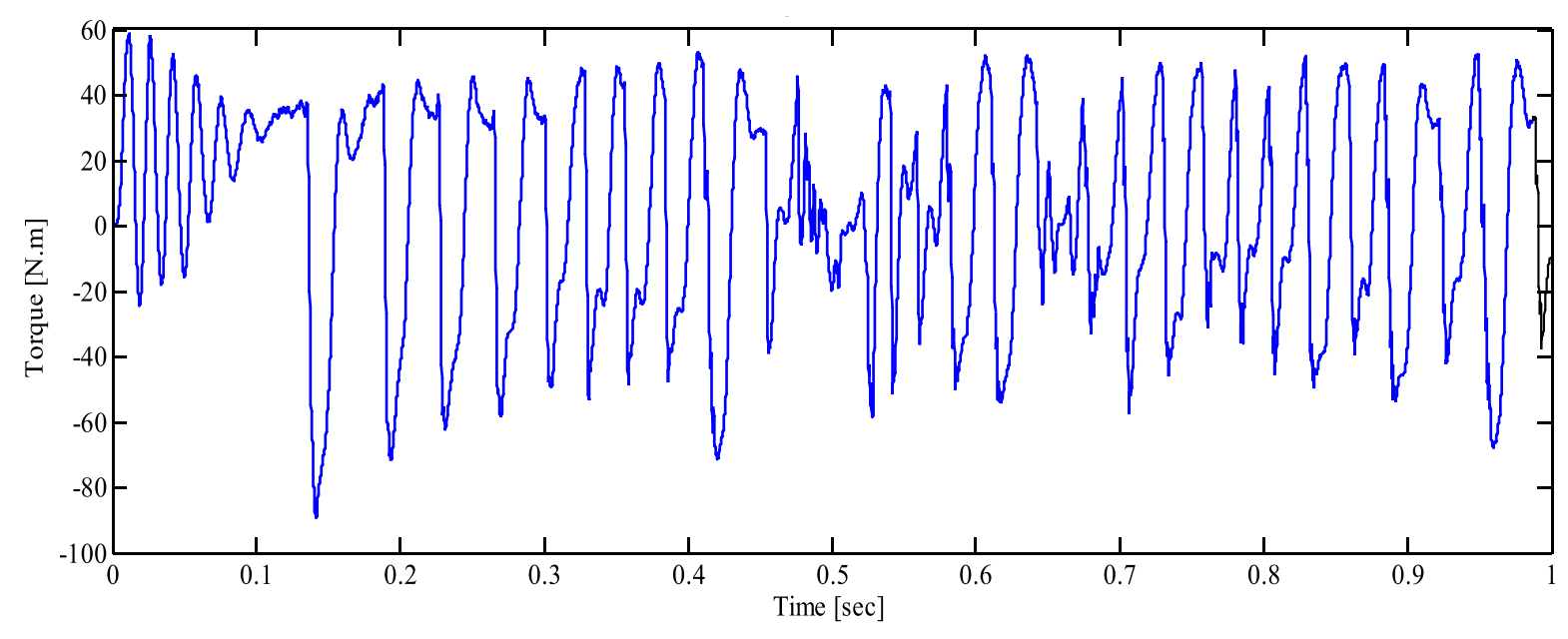

FIG. 14. ELECTROMAGNETIC TORQUE OF INDUCTION MOTOR DRIVE WITH SVPWM

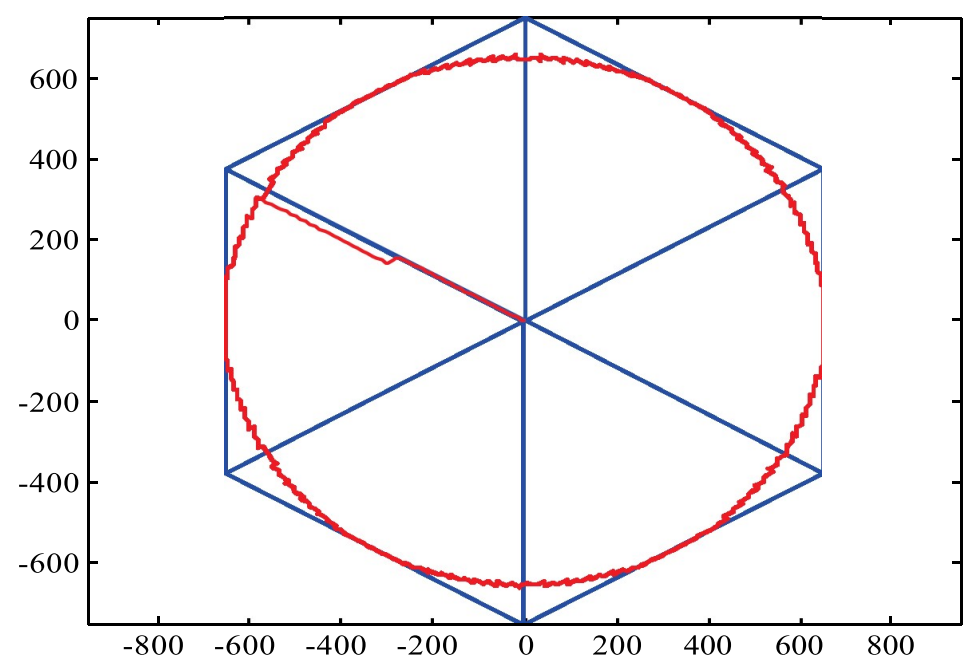

FIG.15 SPECE VECTOR TRAJECTORY

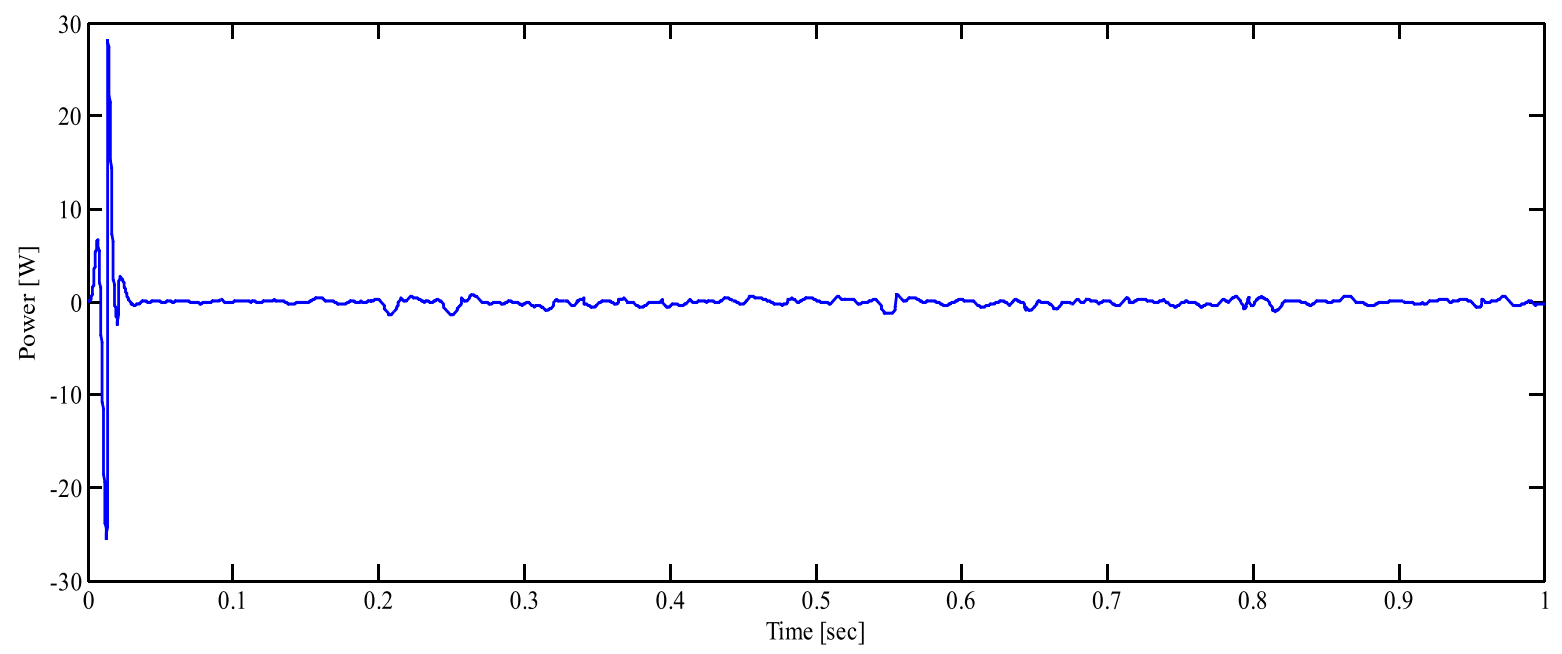

FIG.16 SWITVHING LOSSES OF INVERTER WITH SVPWM 

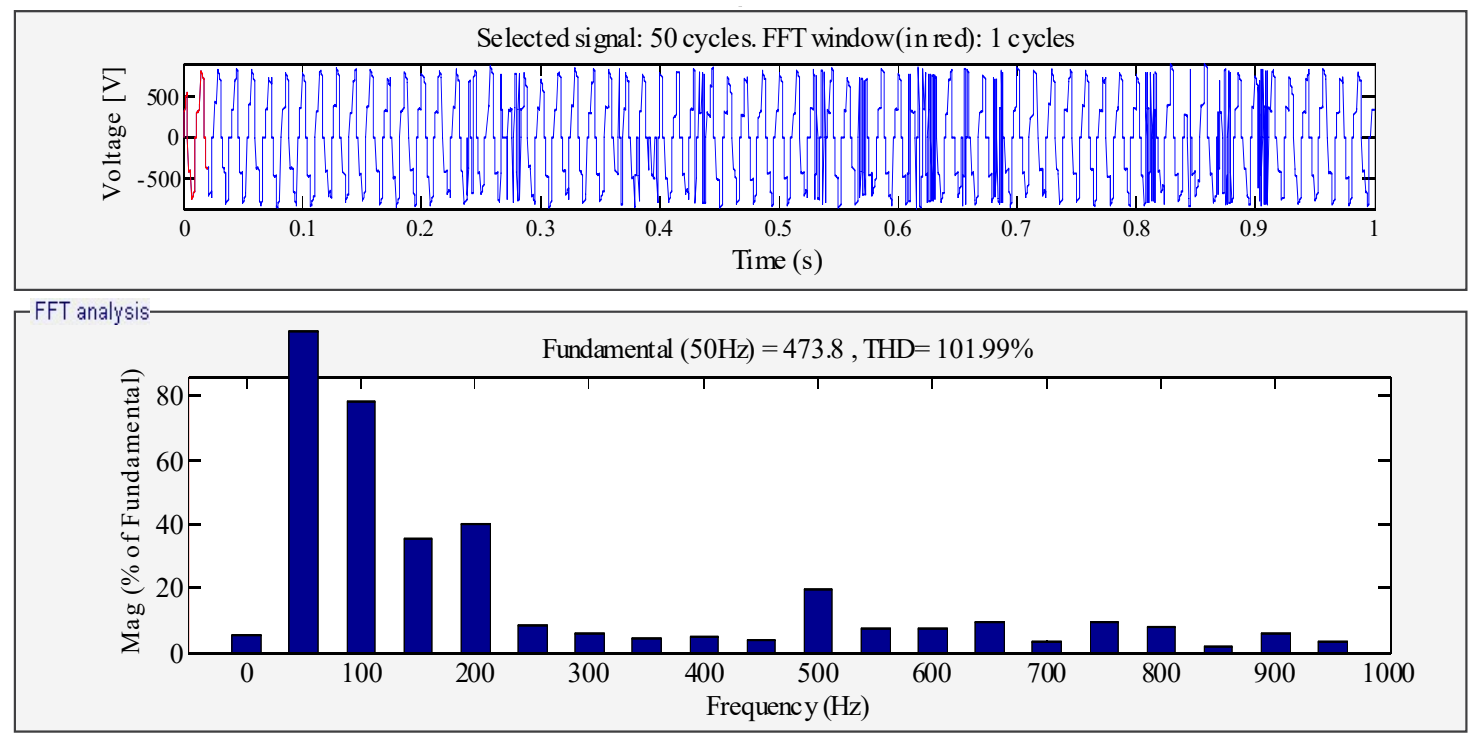

FIG.17. INPUT VOLTAGE TO MOTOR AND ITS HARMONIC ANALYSIS WITH SPWM
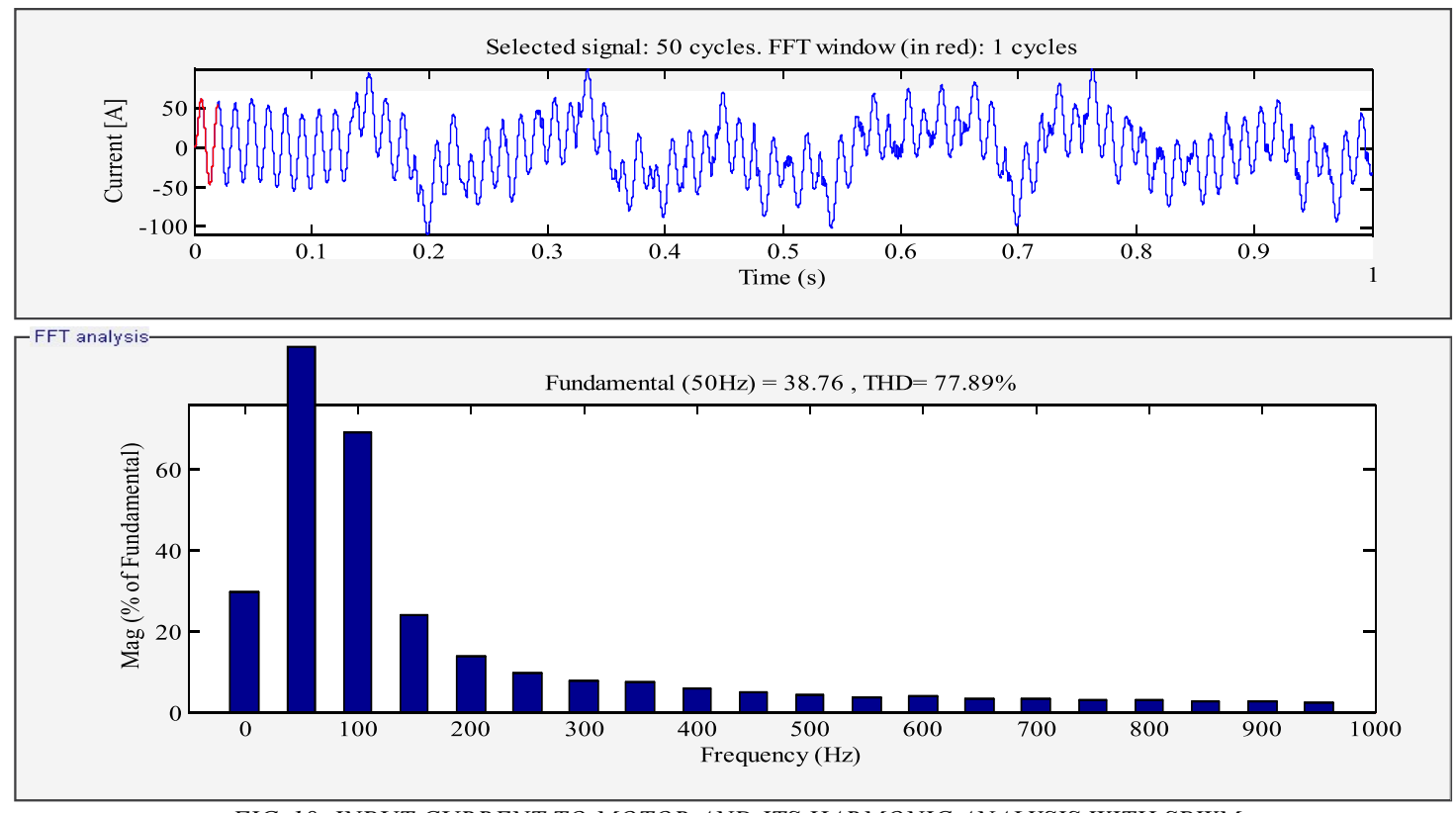

FIG. 18. INPUT CURRENT TO MOTOR AND ITS HARMONIC ANALYSIS WITH SPWM

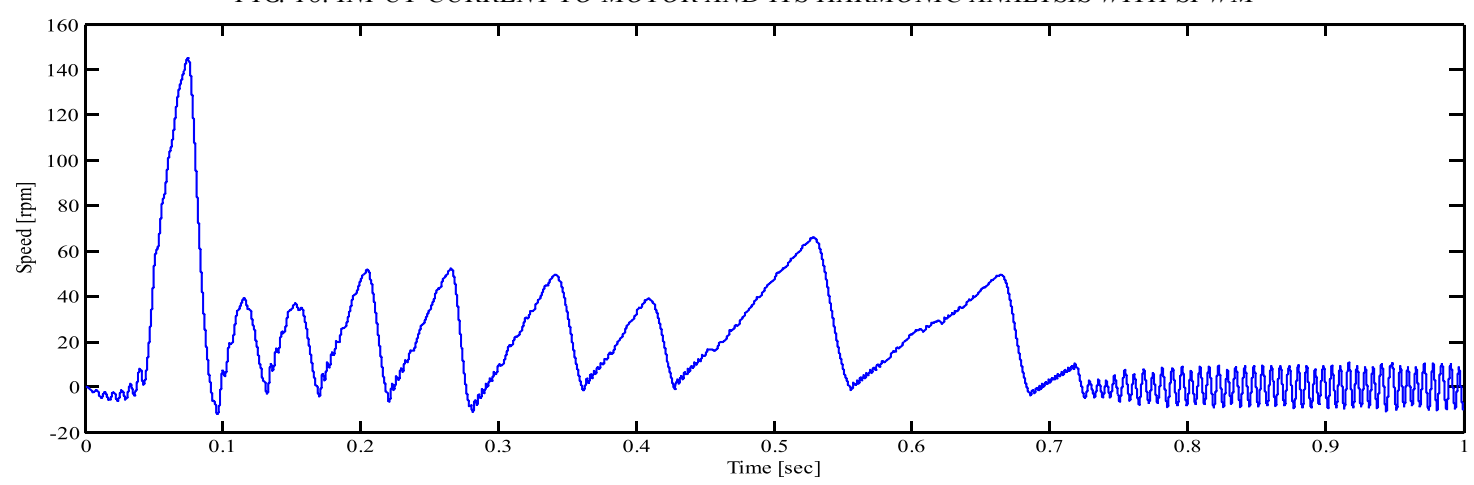

FIG. 19. ROTOR SPEED OF INDUCTION MOTOR DRIVE WITH SPWM 
The comparative results on the basis of THD and switching losses of SPWM and SVPWM techniques, with and without filter are shown in Table2. A low pass filter of second order with cut off frequency of $200 \mathrm{~Hz}$ and damping factor 0.707 is used to filter out the harmonics from the outputs of VSI.

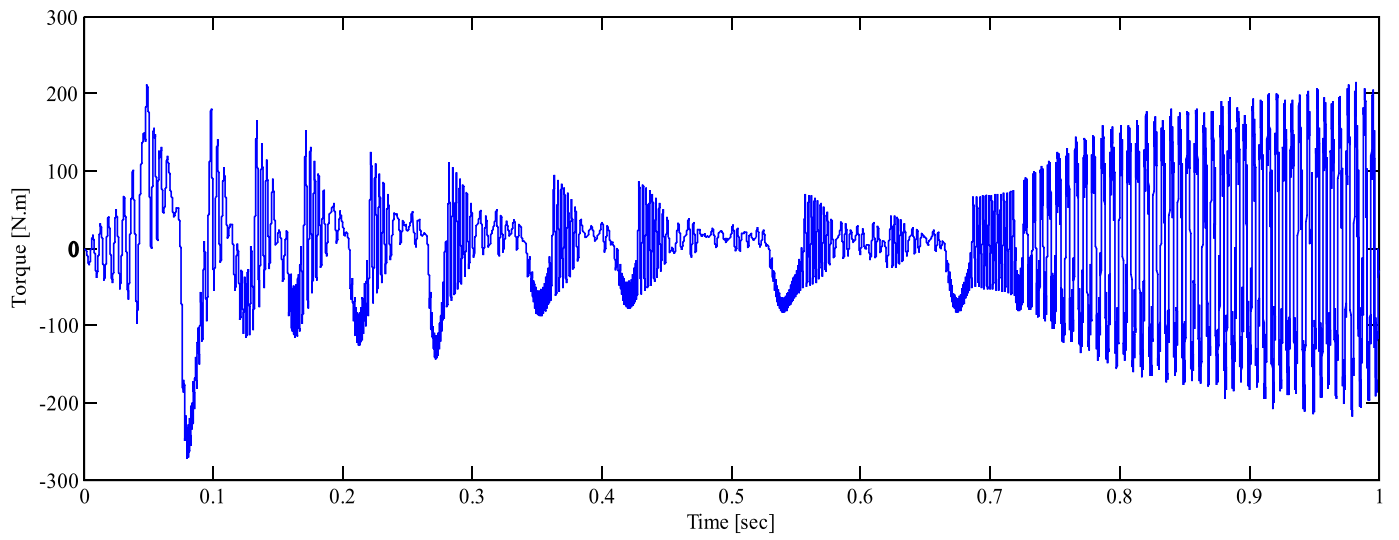

FIG. 20. ELECTROMAGNETIC TORQUE OF INDUCTION MOTOR DRIVE WITH SPWM

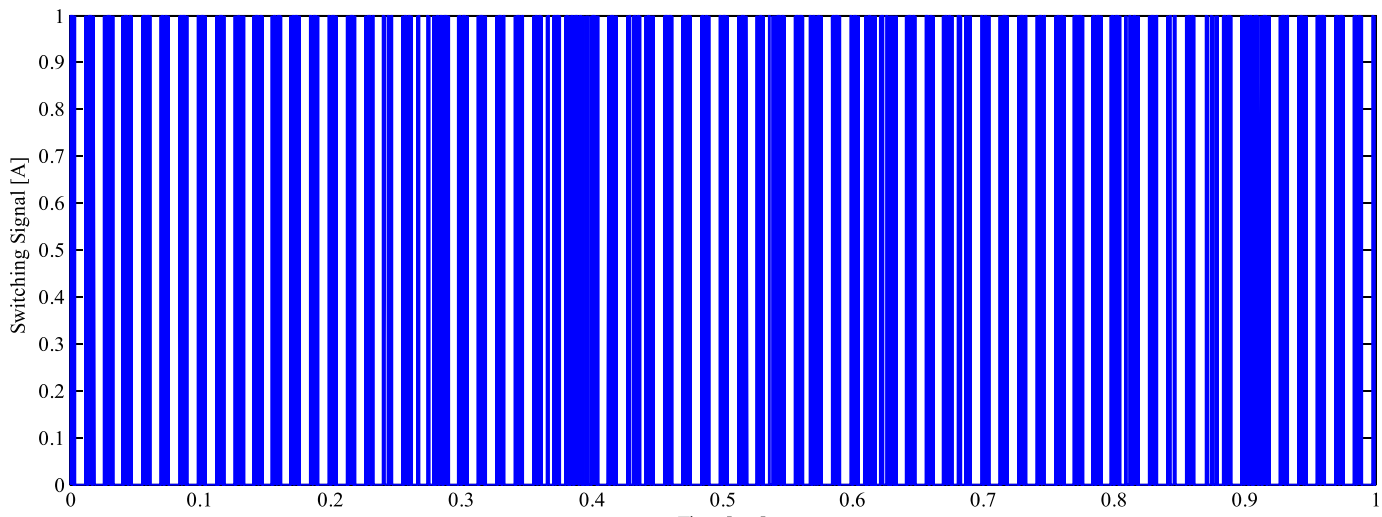

FIG.21. SPWM SWITCHING SIGNAL FOR VSI

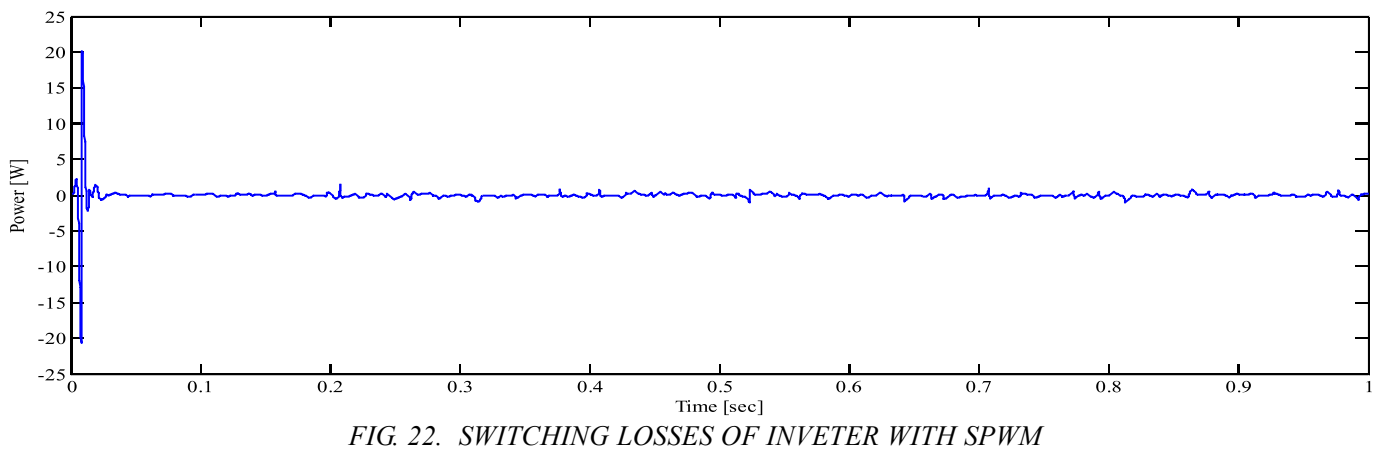

TABLE 2. COMPARATIVE ANALYSIS

\begin{tabular}{|c|c|c|c|c|c|}
\hline \multirow{2}{*}{\multicolumn{2}{|c|}{ Parameter }} & \multicolumn{2}{|c|}{ Without Filter } & \multicolumn{2}{|c|}{ With Filter } \\
\hline & & SPWM & SVPWM & SPWM & SVPWM \\
\hline \multirow{2}{*}{ THD (\%) } & Voltage & 101.99 & 73.23 & 75.89 & 46.65 \\
\hline & Current & 77.89 & 63.3 & 52.43 & 34.76 \\
\hline \multicolumn{2}{|c|}{ Switching Losses (Mw) } & 269.45 & 178.79 & 269.45 & 178.79 \\
\hline
\end{tabular}

Mehran University Research Journal of Engineering \& Technology, Volume 39, No. 1, January, 2020 [p-ISSN: 0254-7821, e-ISSN: 2413-7219] 


\subsection{Practical Results}

The laboratory setup for induction motor drive control is shown in Fig.23. The motor is supplied with $400 \mathrm{~V} / 230$ VY/". The name plate data of motor is shown in Fig. 24. The interface of vector controller and its ratings are shown in Figs. 25-26. The motor was controlled with and without the boost converter.In order to maintain the constant flux density at low frequencies and speeds, the applied voltage to frequency ration (V/F) should be kept constant. V/F control is more efficient and also improves the starting performance of drive. For compensating the effects of stator resistance, the voltage must be boosted at low frequencies. The V/F curves with and without boost are shown in Fig. 27.

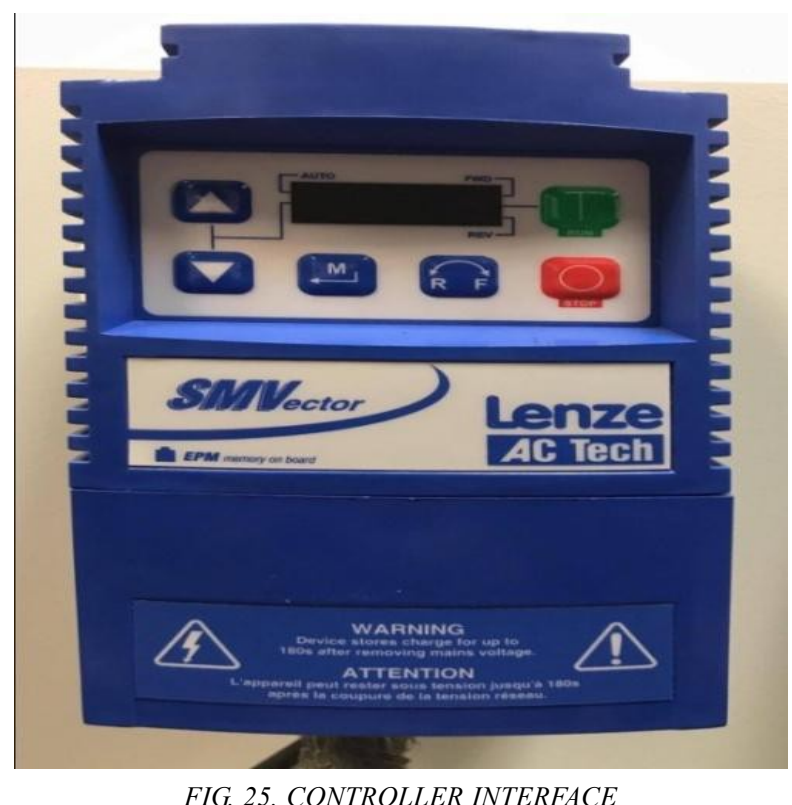

FIG. 25. CONTROLLER INTERFACE

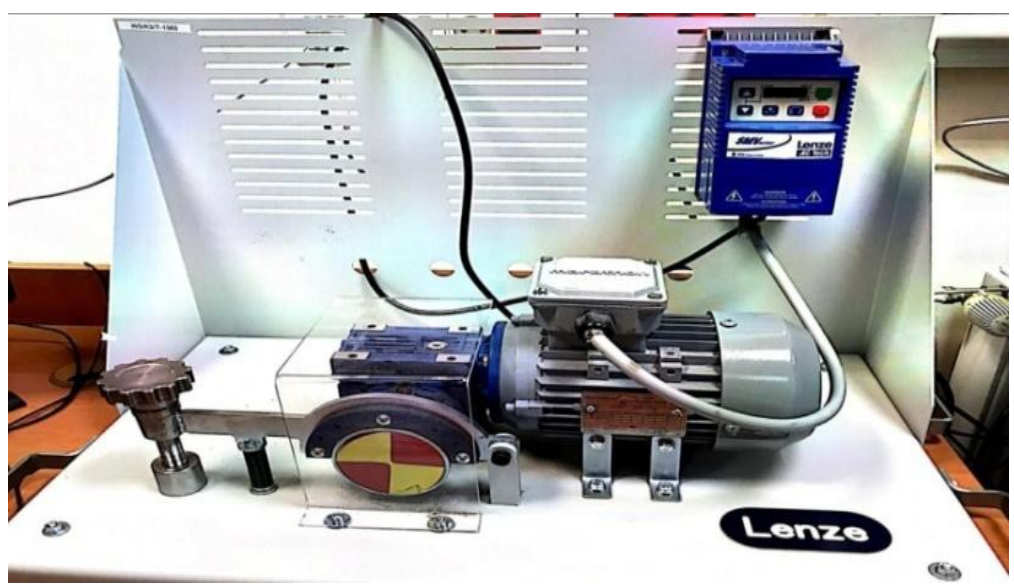

FIG.23. EXPERIMENTAL LABORATORY SETUP

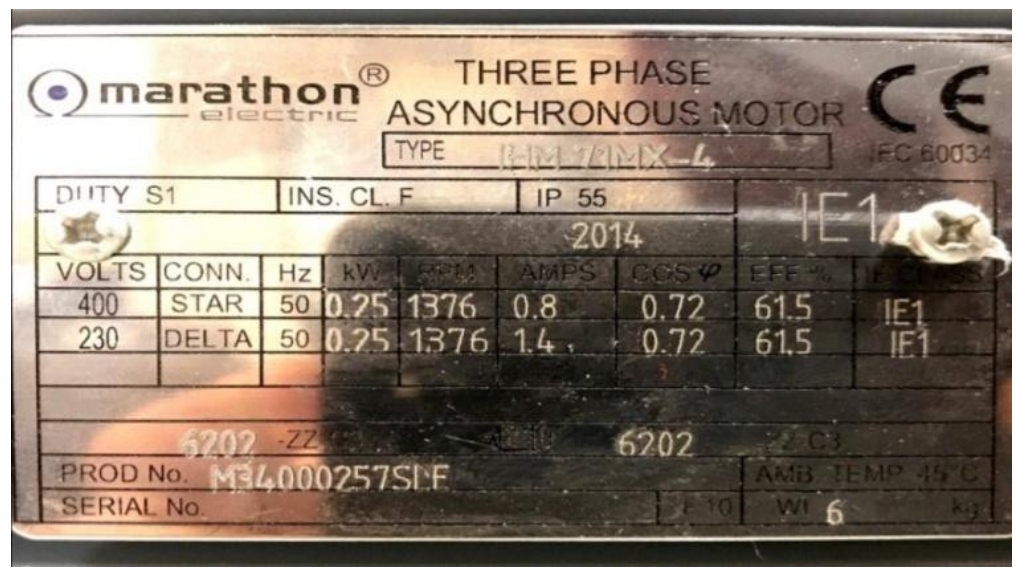

FIG. 24. NAME PLATE DATA OF INDUCTION MOTOR

Mehran University Research Journal of Engineering \& Technology, Volume 39, No. 1, January, 2020 [p-ISSN: 0254-7821, e-ISSN: 2413-7219] 


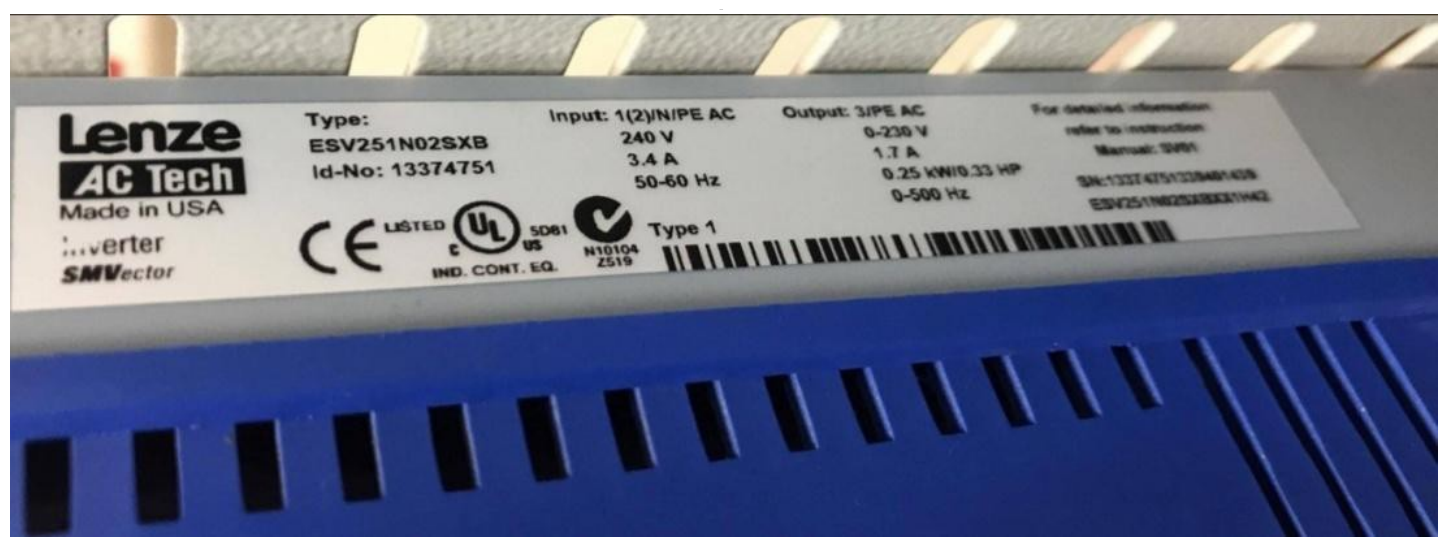

FIG. 26. RATINGS OF CONTROLLER

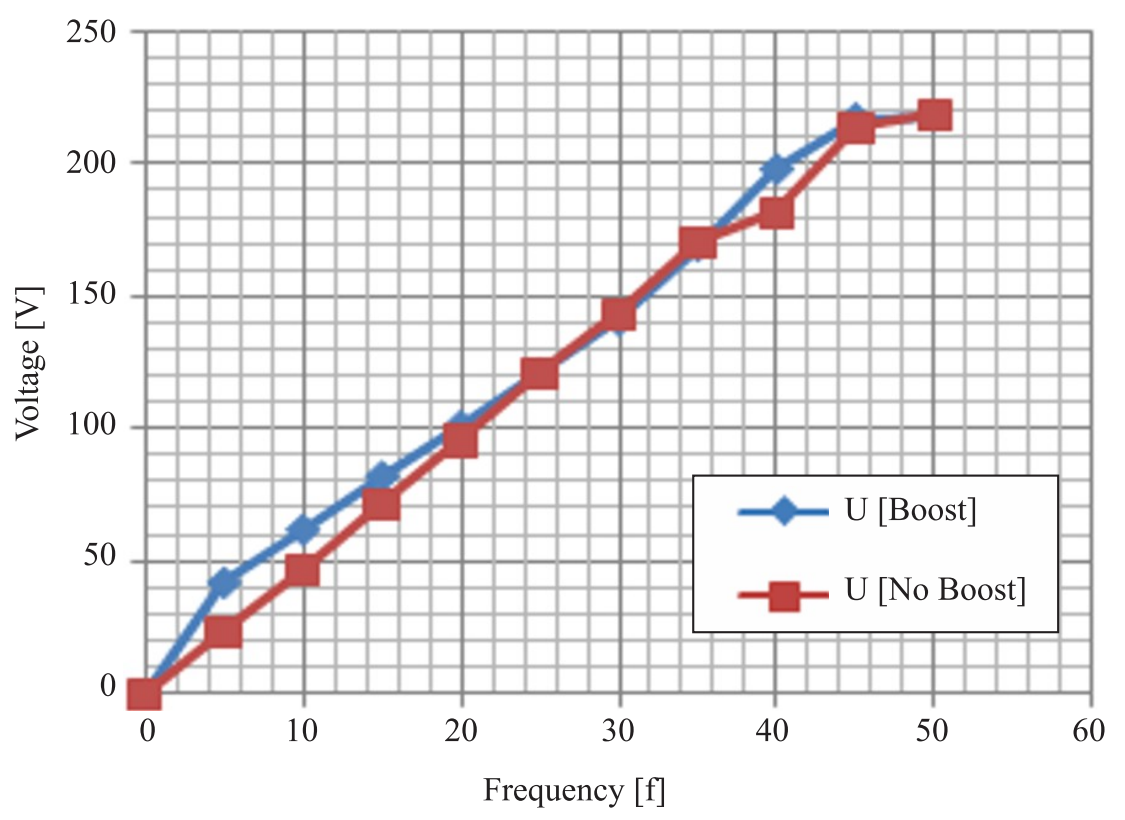

FIG. 27. VOLTAGE V/S FREQUENCY GRAPH

\section{CONCLUSION}

This research work was carried out to find out the performance of SVPWM for controlling output of induction motor through two-level VSI at desirable level of harmonics and switching losses. The comparative analysis between SPWM and SVPWM techniques was made. From the THD graph, it was observed that SVPWM technique does contribute to sub-harmonics within the given range of modulation index i.e. 0.5-0.9. From the comparison, it was also seen that THD and switching losses of SVPWM were smaller as compared to SPWM because the SVPWM technique utilized greater amount of DC link voltage and the output of converter was higher. The output speed and torque of induction motor were more favorable with SVPWM as compared to SPWM. Detailed mathematical and Simulink modeling was done to ensure the efficacy of propositions. The practical results for $\mathrm{V} / \mathrm{F}$ control of IM drive with and without boost were also promising with SVPWM technique. 


\section{FUTURE RECOMMENDATION}

In future, MMCs (Multi-Modular Converters) with SVPWM can be applied to control the torque and speed of induction motors. With MMCs, the desired power quality and switching frequency can be obtained at higher converter levels. The set up can be arranged with FPGA (FieldProgrammable Gate Array) cards running on the PHIL (Power-Hardware-In-Loop) system for multitasking as in smart grid system.

\section{ACKNOWLEDGMENT}

Authors are thankful to Wroclaw University of Science $\&$ Technology, Poland, for providing access to their lab for conducting this research work. Additionally, first author is thankful to Sukkur Institute of Business Administration University, Sukkur, Pakistan for their exceptional support and coordination in all research projects.

\section{REFERENCES}

[1] Sahoo, S.K., Ramulu, A., Batta, S., Duggal, S., "Performance Analysis and Simulation of Three Phase Voltage Source Inverter Using Basic PWM Techniques", IET Chennai 3rd International on Sustainable Energy and Intelligent Systems, 2012 .

[2] Jacobina, C.B, Correa, M.B.R., Da Silva, E.R.C., and Lima, A.M.N., "Induction Motor Drive System for Low Power Applications", IEEE IAS Annual Meeting Conference Record, pp. 605-612, New Orleans, Louisiana, USA, 1997.

[3] Alexa, I.A., Onea, A., "Fast Calculating PWM Technique of Voltage Source Inverter", Proceedings of IEEE System Theory Control and Computing, October 2014.

[4] Dhekekar, R.S., and Sonune, M.S., "Study of Performance Analysis of H-Bridge VSI with Sinusoidal Pulse Width Modulation", International Journal of Engineering Research and Technology, Volume 3, No. 12, December, 2014.
[5] Ramirez, F.A., Arjona, M.A., and Hernandez, C., “A Space Vector PWM Voltage-Source Inverter for a Three Phase Induction Motor Based on the dsPIC30F3011", Conference on Electronics, Robotics and Automotive Mechanics, Cuernavaca, 2009.

[6] Jae-Hyeong, S., Chang, H.C., and Dong, S.H., "A New Simplified Space-Vector PWM Method for Three-Level Inverters", IEEE Transactions on Power. Electronic, Volume 16, pp. 545-550, July, 2001.

[7] Busquets-Monge, S., Bordonau, J., Boroyevich, D., and SoMavilla, S., "The Nearest Three Virtual Space Vector PWM - A Modulation for the Comprehensive Neutral-Point Balancing in the Three-Level NPC Inverter", IEEE Power Electronics Letters, Volume 2, No. 1, pp. 11-15, March, 2004.

[8] Leedy, A.W., and Nelms, R.M., "Harmonic Analysis of a Space Vector PWM Inverter Using the Method of Multiple Pulses", Proceedings of IEEE International Symposium on Industrial Electronic, pp. 1188-1192, Jul, 9-12, 2006.

[9] Lee, M.Y., Wheeler, P., and Klumpner, C., "Space-Vector Modulated Multilevel Matrix Converter," IEEE Transactions on Industrial Electronics, Volume 57, No. 10, pp. $3385-3394,2010$.

[10] Yuan, Z., and Cheng, J., "Research on Space Vector PWM Inverter Based on Artificial Neural Network", $6^{\text {th }}$ International Symposium on Computational Intelligence and Design, 2013.

[11] Nayeemuddin, T., Bramhananda, R.M., and Kumar, V., "Space Vector Based Random PWMAlgorithms for Acoustic Noise and Harmonics Reduction for Voltage Source Inverter Fed AC Drive", Energy Procedia, Volume 117, pp. 353-360, June, 2017.

[12] Dorin, O., "Space Vector Modulation - An Introduction" IEEE Annual Conference on Industrial Electronics Society, pp. 1583-1592, 2001.

[13] Mohamed, A., Anish, G.A., and Baiju, M., "A Simple Space Vector PWM Generation Scheme for any General n-Level Inverter", IEEE Transactions on Industrial Electronic, Volume 56, pp. 1649-1656, May, 2009. 
[14] Aspalli, M., and Wamanrao, A., "Sinusoidal Pulse Width Modulation with Variable Carrier Synchronization for Multilevel Inverter Controllers", International Conference on Control, Automation, Communication and Energy Conservation, pp. 1-6, 2009.

[15] Orlowska-Kowalska, T., and Tarchala, G., "Unified Approach to the Sliding-Mode Control and State EstimationApplication to the Induction Motor Drive", Bulletin of the Polish Academy of Sciences: Technical Sciences, Volume 61, No. 4, pp. 837-846, 2013
[16] Katyara, S., Shah, M.A., Staszewski, L., and Soomro, J., "Harmonics Compensation in Industrial Power Network Using Hybrid Active Power Filter (HAPF) in d-q Frame", Sindh University Research Journal (Science Series), Volume 49, No. 4, pp. 881-888, Jamshoro, Pakistan, 2017.

[17] Mazgaj, W., Rozegnal, B., and Szular, Z., "Switching Losses in Three-Phase Voltage Source Inverters", Czasopismo Techniczne, Elektrotechnika Zeszyt, Volume 2E, No. 13, pp. 47-60, 2015. 